\title{
Octreotide for the treatment of intentional insulin aspart overdose in a non-diabetic patient
}

\author{
Catherine M. Dewaal, BScPharm, PharmD*; Eric McGillis, MD ${ }^{\dagger \S}$; Matt Mink, BSP ${ }^{\ddagger}$; \\ Scott Lucyk, MD
}

\begin{abstract}
Intentional insulin overdose may lead to severe and refractory hypoglycemia. Exogenous dextrose administration is the mainstay of therapy for these patients and is effective in most cases. However, in patients with a functional pancreas, exogenous dextrose administration may precipitate endogenous insulin release leading to rebound hypoglycemia. We describe a case report of a 41-year-old woman who injected 300 units of insulin aspart with suicidal intent. Her initial blood glucose was $2.3 \mathrm{mmol} / \mathrm{L}(41 \mathrm{mg} / \mathrm{dL})$. Over the next 12 hours, she experienced recurrent hypoglycemic episodes despite $10 \%$ dextrose infusions and 14 ampoules of $50 \%$ dextrose. Our patient experienced complications, including peripheral edema, related to the large volumes of intravenous dextrose required to attempt to maintain euglycemia. Octreotide, a somatostatin analogue, may help prevent dextrose-induced hypoglycemia and improve the management in select insulin overdose patients; large infusion volumes resulted in significant peripheral edema. Treatment with octreotide was initiated 12.5 hours post-injection and was followed by a stabilization of blood glucose concentration in this nondiabetic patient.
\end{abstract}

\section{RÉSUMÉ}

Une surdose intentionnelle d'insuline peut entraîner une hypoglycémie très grave, réfractaire au traitement. Celui-ci consiste principalement en l'administration de dextrose exogène, et il se montre efficace dans la plupart des cas. Toutefois, chez les personnes chez qui le pancréas est en état de fonctionnement, l'administration de dextrose exogène peut provoquer la libération endogène d'insuline, ce qui peut provoquer à son tour une hypoglycémie rebond. Sera exposé ici le cas d'une femme de 41 ans, aux idées suicidaires, qui s'est injectée 300 unités d'insuline aspart. À l'arrivée de la patiente, la glycémie était de $2,3 \mathrm{mmol} / \mathrm{l}(41 \mathrm{mg} / \mathrm{dl})$. $\mathrm{Au}$ cours des 12 heures suivantes, il s'est produit d'autres épisodes d'hypoglycémie, malgré les perfusions de dextrose à $10 \%$ et l'injection de 14 ampoules de dextrose à $50 \%$. S'en sont suivies des complications, notamment un œdème périphérique, lié à l'administration de quantités importantes de dextrose par voie intraveineuse dans le but de maintenir la glycémie normale. Toutefois, l'octréotide, un analogue de la somatostatine, peut aider à prévenir l'hypoglycémie secondaire à l'administration de dextrose et à améliorer la prise en charge des surdoses d'insuline chez certains patients; la perfusion de grandes quantités de liquides s'est soldée par un œdème périphérique important. Le traitement par l'octréotide a été entrepris 12,5 heures après l'injection d'insuline, et il a permis de stabiliser la glycémie chez cette patiente non diabétique.

Keywords: octreotide, insulin, insulin aspart, overdose, dextrose, hypoglycemia

\section{INTRODUCTION}

Intentional insulin overdoses are relatively uncommon, with only 166 cases reported to Canadian poison centres (excluding Quebec) in 2016 (personal communication with Canadian poison centre staff: D Leong [BC], M Mink [AB], M Thompson [ON], A Letarte [QC], and L Mosher [NS]; July 2017). Similarly, U.S. poison centres reported only 592 cases in $2015 .^{1}$ Although uncommon, severe hypoglycemia necessitating frequent blood glucose measurements, active glycemic control, and, in some cases, admission to an intensive care unit may occur. ${ }^{2,3}$ Standard therapy includes enteral feeding and intravenous (IV) dextrose infusions; acute episodic hypoglycemia often mandates treatment with concentrated dextrose boluses. ${ }^{3}$

Octreotide is a semisynthetic, long-acting somatostatin analogue that suppresses endogenous insulin release. ${ }^{4}$ It is commonly used to minimize hypoglycemia following sulfonylurea overdose. ${ }^{3,4}$ Hypoglycemia from sulfonylurea toxicity is largely the result of endogenous insulin release, triggered by the binding of the drug to ATP-sensitive potassium channels. ${ }^{4,5}$ Following an insulin overdose, few case reports have proposed the use of octreotide as an adjunct to standard therapy for dextrose-induced episodic hypoglycemia resulting from endogenous insulin release in non-diabetic and non-insulin-dependent diabetic patients. $^{2,6}$ Purported benefits include reductions in hypoglycemic episodes, IV fluid volume, and total dextrose

From the *Faculty of Pharmacy and Pharmaceutical Sciences, University of Alberta, Edmonton, AB; †Department of Emergency Medicine and ‡Poison and Drug Information Service, Alberta Health Services, Calgary, AB; and §Cumming School of Medicine, University of Calgary, Calgary, AB.

Correspondence to: Dr. Catherine M. Dewaal, Pharmacy Services, South Health Campus, Alberta Health Services, 4448 Front Street SE, Calgary, AB T3M 1M4; Email: catherine.dewaal@albertahealthservices.ca 
requirements. ${ }^{3,4} \mathrm{We}$ report a unique case of subcutaneous (SC) octreotide use in a non-diabetic patient following an intentional overdose with insulin aspart.

\section{CASE REPORT}

A 41-year-old, non-diabetic woman purchased insulin aspart from an online Canadian pharmacy and injected 300 units SC into a single site on her abdomen with suicidal intent. She also ingested $45 \mathrm{mg}$ of zopiclone, $2 \mathrm{mg}$ of clonazepam, and six vodka coolers. She contacted a friend who subsequently alerted Emergency Medical Services; paramedics identified the product found in the patient's home as NovoRapid, a brand name of insulin aspart. Approximately 40 minutes after the insulin injection, paramedics found her to be ataxic, lethargic, and diaphoretic, with normal vital signs and an initial glucose of $2.3 \mathrm{mmol} / \mathrm{L}(41 \mathrm{mg} / \mathrm{dL})$. She immediately received a $50-\mathrm{mL}$ ampoule of $50 \%$ dextrose (D50W). During transport to the hospital, a second dose was administered for recurrent hypoglycemia. Upon arrival to the emergency department (ED), her glucose was $8.4 \mathrm{mmol} / \mathrm{L}(151 \mathrm{mg} / \mathrm{dL})$.

In the ED, 1.5 hours post-injection, her vital signs were blood pressure, 95/51 $\mathrm{mm} \mathrm{Hg}$; heart rate, 78/min; respiratory rate, $16 / \mathrm{min}$; oxygen saturation, $94 \%$ on room air; temperature, $36.3 \mathrm{C}$. She was drowsy but responded to questions appropriately. She denied ingesting any other hypoglycemic agents, including sulfonylureas. The rest of her physical examination was unremarkable. Acetaminophen and salicylate concentrations were negative. Laboratory values of note included a serum ethanol concentration of $26 \mathrm{mmol} / \mathrm{L}$ $(120 \mathrm{mg} / \mathrm{dL})$ and a serum potassium of $2.7 \mathrm{mEq} / \mathrm{L}$, for which she received $40 \mathrm{mmol}$ potassium chloride in $1000 \mathrm{~mL}$ of normal saline, infused at $150 \mathrm{~mL} / \mathrm{h}$.

During her initial 10 hours in the ED, she received approximately $2000 \mathrm{~mL}$ of $10 \%$ dextrose solution IV at rates of $250-425 \mathrm{~mL} / \mathrm{h}$. An additional 12 ampoules of D50W were administered for recurrent hypoglycemia, arbitrarily defined by the admitting service as glucose $<3.8 \mathrm{mmol} / \mathrm{L}(<68 \mathrm{mg} / \mathrm{dL})$. Eating and drinking were encouraged, but she refused. Total IV fluid administration during the 10-hour period totalled approximately $4000 \mathrm{~mL}$.

At 11.5 hours post-injection, she was assessed by the medical toxicology service and noted to be diffusely edematous. The admitting service was considering placement of a central venous catheter so that lower volumes of more concentrated dextrose solutions could be administered. Upon recommendation by a medical toxicologist, octreotide, $50 \mathrm{mcg}$ SC every 6 hours, was initiated. Her first dose accompanied an additional ampoule of D50W for a blood glucose of $2.9 \mathrm{mmol} / \mathrm{L}$ $(52 \mathrm{mg} / \mathrm{dL})$ at 12.5 hours post-injection.

Shortly following the first dose of octreotide, blood glucose control stabilized (Figure 1). No further D50W was required and her dextrose infusion was slowly weaned and discontinued 36.5 hours after her overdose. She received a total of four doses of octreotide and was observed on a medical ward for 48 hours before being transferred to a psychiatric unit.

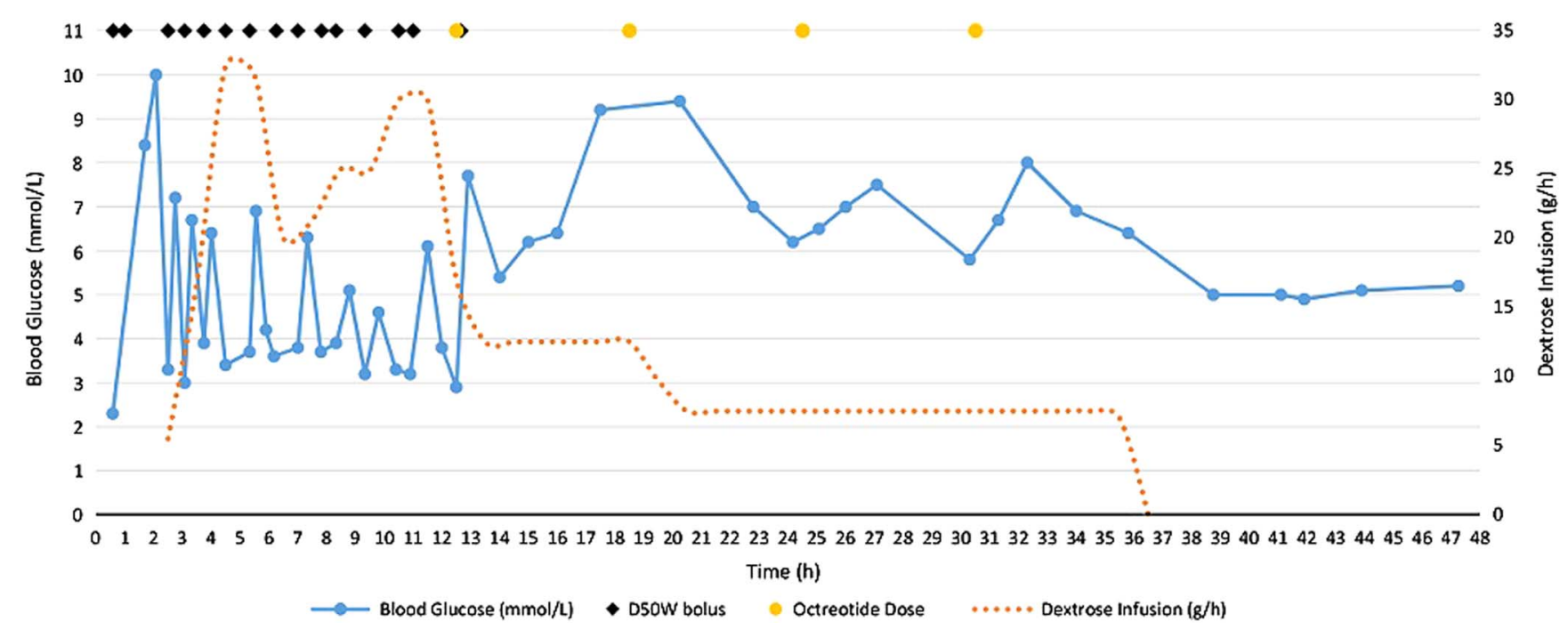

Figure 1. Blood glucose trends and dextrose requirements for 48 hours after intentional insulin aspart overdose. 


\section{DISCUSSION}

This case report describes a large intentional insulin overdose in a non-diabetic patient causing recurrent hypoglycemia, despite large volumes of IV dextrose. Treatment with SC octreotide was initiated 12.5 hours after an insulin injection, at which point her blood glucose concentrations stabilized, and she tolerated a tapering of her dextrose infusions.

When used therapeutically, insulin aspart has a duration of action ranging from 3 to 5 hours. ${ }^{7}$ In overdose, the toxicokinetics of insulin aspart differ vastly from its pharmacokinetics, and hypoglycemia may be prolonged for a number of reasons (Table 1). Consequently, dextrose infusions may be required for multiple days, and higher injected doses appear to correlate with a requirement for longer infusion durations. ${ }^{2,3,11,12}$ In this case, the large dose and single abdominal injection site were likely the most significant contributors to the prolonged hypoglycemia that occurred.

The administration of dextrose, either IV or enteral, following an insulin overdose is the mainstay of therapy. Treatment with IV dextrose solutions is not without risks, including phlebitis (risk increases with concentration), hyperglycemia, and complications related to serum hyperosmolality. ${ }^{3}$ Patients may also develop pulmonary edema, heart failure, and electrolyte abnormalities as a result of fluid overload and osmotic shifts. ${ }^{3,6}$ After 10 hours of IV dextrose, our patient developed significant peripheral edema, likely due to a combination of the fluid volume and large sodium and glucose loads administered to an initially euvolemic patient. Considerations were being made to increase the concentration of the dextrose infusion, which would have necessitated the insertion of a central venous catheter for administration. ${ }^{2}$

In overdoses involving insulin secretagogues, such as sulfonylureas and meglitinides, treating hypoglycemia with dextrose boluses can trigger physiologic insulin release in patients with functioning pancreatic cells, complicating the management of these poisonings. ${ }^{3}$ This same phenomenon, though less well described, can occur in an insulin overdose and likely explains the recurrent hypoglycemia observed in our non-diabetic patient following D50W boluses (see Figure 1). ${ }^{3,6}$ Besides oral hypoglycemic agents and insulins, other drug-related causes of hypoglycemia to consider in the differential diagnosis include quinine, sulfonamides, valproic acid, venlafaxine, beta blockers, and salicylates. ${ }^{12}$

Octreotide binds to somatostatin-2 receptors on the beta-cell calcium channel, inhibiting calcium influx. This, in turn, prevents exocytosis of insulin-containing

\begin{tabular}{|c|c|c|}
\hline \multirow[t]{5}{*}{ Administration route } & Single injection site & Potential depot effect: slowing absorption and prolonging hypoglycemia ${ }^{3}$ \\
\hline & Multiple injection sites & Increased surface area enhances absorption; insulin is cleared more rapidly ${ }^{3}$ \\
\hline & Anatomical location of injection & Insulin aspart: Cmax: abdomen $>$ thigh $^{7}$ \\
\hline & & Regular insulin; $T_{\max }$ : deltoid, gluteal, and femoral areas $>$ abdomen $^{8}$ \\
\hline & Injection technique & $\begin{array}{l}\text { IM injections are more rapidly absorbed than SC injections, a result of higher } \\
\text { blood flow in muscle tissue }\end{array}$ \\
\hline \multirow[t]{2}{*}{ Injected dose } & Large doses & $\begin{array}{l}\text { Insulin type (long v. rapid acting) has less impact than overall dose on duration } \\
\text { of hypoglycemia in } \mathrm{OD}^{3}\end{array}$ \\
\hline & & $\begin{array}{l}\text { Exogenous insulin saturates insulin receptors, extending duration of action; } \\
\text { hypoglycemia is prolonged }\end{array}$ \\
\hline \multirow[t]{2}{*}{ Lipid stores } & Obesity & Prolonged absorption time ${ }^{6}$ \\
\hline & Lipodystrophy & Decreased absorption; prolonged hypoglycemia 9,10 \\
\hline \multirow[t]{3}{*}{ Individual susceptibility } & Diabetic physiology & Potential for reduced severity of hypoglycemia ${ }^{6}$ \\
\hline & & $\begin{array}{l}\text { Anti-insulin antibodies in long-standing diabetic patients may lead to } \\
\text { decreased absorption and prolonged effects }{ }^{9}\end{array}$ \\
\hline & Non-diabetic physiology & $\begin{array}{l}\text { Endogenous insulin released in response to dextrose therapy can cause } \\
\text { recurrent episodic hypoglycemia }{ }^{5}\end{array}$ \\
\hline Organ function & Renal and hepatic dysfunction & $\begin{array}{l}\text { Delayed clearance and prolonged half-life in some insulin preparations (note: } \\
\text { effects not observed with insulin aspart) }\end{array}$ \\
\hline Other factors & $\begin{array}{l}\text { Massaging or heating injection } \\
\text { site, physical activity }\end{array}$ & Speeds absorption time; hypoglycemic effects occur more rapidly 7,8 \\
\hline
\end{tabular}


vesicles. ${ }^{3,4}$ Treatment with octreotide following an insulin overdose may be expected to benefit nondiabetic and non-insulin-dependent diabetic patients whose functional pancreatic beta-cells are capable of releasing endogenous insulin in response to supplemental dextrose. ${ }^{6}$ Specifically, octreotide may benefit patients susceptible to fluid overload by decreasing the volume of dextrose-containing fluids required to maintain euglycemia. ${ }^{6}$ No beneficial effect is expected in the insulin-dependent patient with minimal or no endogenous insulin secretion. ${ }^{5}$ One case report describes the effective use of octreotide in an insulin glargine overdose patient who could not tolerate excess fluid volume due to heart failure and renal impairment. ${ }^{6}$ The authors reported stabilization of blood glucose concentrations after several doses of octreotide. ${ }^{6}$

Onset of action of octreotide occurs within 30 minutes of an SC injection, and peak effects are seen at 4-8 hours. ${ }^{6}$ Our patient achieved euglycemia soon after octreotide initiation, keeping with the predicted clinical effects of the drug. Octreotide is generally well tolerated, with nausea, vomiting, and the injection site pain being the most commonly reported adverse effects. ${ }^{3,6,7}$ No adverse effects were reported during the treatment of our patient.

A potential downside to octreotide use is that it also suppresses endogenous glucagon secretion, inhibiting the body's natural biological response to hypoglycemia. ${ }^{3,4,5}$ Although it may seem counterproductive to inhibit this action, studies of octreotide use in sulfonylurea toxicity have shown that its administration reduces both endogenous insulin levels and the incidence of recurrent hypoglycemia. ${ }^{10}$ In this case, where the patient's normal physiologic insulin release in response to dextrose administration was presumably complicating her treatment, the authors felt that the benefits of inhibiting insulin secretion outweighed the risks of suppressing glucagon activity.

We recognize that our case report has some limitations. It is possible that, at the time of the octreotide administration, the insulin effects were also starting to wane and that stabilization of blood glucose was due to a dissipating insulin effect. We feel that this is unlikely because Figure 1 clearly shows that the recurrent hypoglycemic episodes occurring after each D50W bolus were not decreasing in frequency or severity prior to the initiation of octreotide. Additionally, the patient had several co-ingestions, including zopiclone, clonazepam, and ethanol. However, zopiclone and clonazepam are not expected to affect blood glucose, and acute ethanol ingestion in a nonalcoholic, such as our patient, would not be expected to cause persistent and recurrent hypoglycemia. Even if mild hypoglycemia did occur as a consequence of alcohol ingestion, recurrent episodes following D50W boluses would not be expected. Finally, the first dose of octreotide was administered at the same time as her final D50W dose, so the full effect of octreotide could not be appreciated until the effects of the dextrose bolus wore off.

Another limitation in our report relates to the lack of supportive laboratory data, specifically C-peptide and proinsulin concentrations. Insulin is secreted from pancreatic beta-cells as proinsulin, which is subsequently cleaved to form insulin and C-peptide. In this case of known exogenous insulin overdose, C-peptide levels could be used as a measurement of endogenous insulin release. Unfortunately, in the region where this patient was treated, C-peptide levels are only processed by an external laboratory once per week, precluding its utilization in the acute care setting. The use of octreotide in future insulin overdose situations should be accompanied by the measurement of C-peptide levels before and after octreotide administration, if available. Although levels would not contribute to the acute treatment of the patient, it could provide an indication of endogenous insulin release. Lastly, because the patient's history and clinical presentation were consistent with an insulin overdose, we did not send comprehensive drug screens or drug concentrations, specifically oral hypoglycemic assays, to rule out potential co-ingestion. Importantly, a single case report of octreotide use in insulin overdose is insufficient to warrant a change in practice recommendations for the vast majority of patients.

In summary, the majority of insulin overdose presentations will respond to supportive measures with enteral feeding and IV dextrose. In this case, the patient did not tolerate the large fluid volumes required to maintain euglycemia, and glucose concentrations did not stabilize until after octreotide was administered. Further studies and a careful patient selection required before the use of octreotide following insulin overdose in non-diabetic and non-insulin-dependent diabetic patients can be routinely recommended.

\section{CONCLUSION}

Emergency physicians should be aware of the severe and refractory hypoglycemia that may occur following 
an insulin overdose. Although exogenous dextrose administration is the mainstay of therapy, in select non-diabetic patients with normal pancreatic function, endogenous insulin release may lead to recurrent hypoglycemia. In addition, prolonged dextrose infusions are not without risk, including volume overload and peripheral edema. The appropriate use of octreotide in select patients who cannot tolerate or who have complications from exogenous dextrose may help stabilize blood glucose concentrations. Because insulin overdose presentations are relatively uncommon, it is important to involve local poison control centres in the management of these patients.

Competing interests: None declared.

\section{REFERENCES}

1. Mowry JB, Spyker DA, Brooks DE, et al. 2015. Annual Report of the American Association of Poison Control Centers' National Poison Data System (NPDS): 33rd annual report. Clin Toxicol 2016;54(10):924-1109, doi: $10.1080 / 15563650.2016 .1245421$.

2. Lu M, Inboriboon PC. Lantus insulin overdose: a case report. 7 Emerg Med 2011;41(4):374-77.
3. Klein-Schwartz W, Stassinos GL, Isbister GK. Treatment of sulfonylurea and insulin overdose. $\mathrm{Br} f \mathrm{Clin}$ Pharmacol 2015;81(3):496-504.

4. Glatstein M, Scolnik D, Bentur Y. Octreotide for the treatment of sulfonylurea poisoning. Clin Toxicol 2012; 50:795-804.

5. Fuller ET, Miller MA, Kaylor DW, et al. Lantus overdose: case presentation and management options. 7 Emerg Med 2009; 36(1):26-9.

6. Groth CM, Banzon ER. Octreotide for the treatment of hypoglycemia after insulin glargine overdose. 7 Emerg Med 2013;45(2):194-8.

7. NovoRapid. Product Monograph. Mississauga, ON: Novo Nordisk Canada Inc.; 2016.

8. Binder C, Lauritzen T, Faber O, et al. Insulin pharmacokinetics. Diabetes Care 1984;7(2):188-99.

9. Efrimescu C, Yagoub E, Doyle R. Intentional insulin overdose associated with minimal hypoglycemic symptoms in a non-diabetic patient. Maedica (Buchar) 2013;8(4): $365-9$

10. Dougherty PP, Klein-Schwartz W. Octreotide's role in the management of sulfonylurea-induced hypoglycemia. $7 \mathrm{Med}$ Toxicol 2010;6:199-206, doi:10.1007/s13181-010-0064-z.

11. Arem R, Zoghbi W. Insulin overdose in eight patients: insulin pharmacokinetics and review of the literature. Medicine 1985;64(5):323-32.

12. Bosse GM. Antidiabetics and hypoglycemics. In Goldfrank's toxicologic emergencies. 10th ed. New York, NY: McGrawHill Education; 2015: 720-31. 